\title{
The Need for Respiratory Support in Acute Leukemia: Frequency, Risk Factors and Prognosis
}

\section{Akut Lösemi Hastalarında Mekanik Ventilasyon İhtiyacı: Sıklık, Risk Faktörleri ve Prognozu Etkileyen Faktörlerin Belirlenmesi}

\author{
Burak Bilgin $^{1}$, Yahya Buyukasik ${ }^{2}$ \\ ${ }^{1}$ Hacettepe University, Department of Internal Medicine \\ ${ }^{2}$ Hacettepe University, Department of Heamatology
}

Dergiye Ulaşma Tarihi: 20.03.2020 Dergiye Kabul Tarihi: 22.06.2020 Doi: 10.5505/aot.2020.15010

\begin{abstract}
ÖZET
GİRIŞ ve AMAÇ: Akut lösemiler kemik iliğinde blastik hücrelerin kontrolsüz çoğalması ile karekterize heterojen bir hastalık grubudur. Tedavi ve hastalık seyrinde yüksek mortalite ve morbidite görülebilir. Bu hasta grubunde solunum yetmezliği yüksek mortalite ile ilişkili bulunmuştur. Bu çalışmada akut lösemi hastalarında solunum destek ihtiyacı gelişim oranının, risk faktörlerinin ve prognostik faktörlerin belirlenmesi amaçlanmıştır. YÖNTEM ve GEREÇLER: 2003-2014 yılları arasında takip edilen tüm akut lösemi hastaları çalışmaya retrospektif olarak dâhil edildi.Ekstrapulmoner nedenle solunum desteği ihtiyacı duyan hastalar risk faktörleri ve prognozun belirlenmesi ile ilgili istatistiksel analizlere dâhil edilmediler Hastaların demografik özellikleri, solunum destek ihtiyacı oranı ve nedenleri, solunum yetmezliği gelişimi için risk faktörleri ve prognozu etkileyen faktörler belirlendi. Solunum desteği gereken hastaların sağkalım analizleri yapıldı. BULGULAR: Toplam 460 hasta çalışmaya dahil edildi. Tüm akut lösemi hastaları arasında \%30,6 oranında solunum desteği verildiği saptand. En sık neden pnömoni idi. Solunum yetmezliği gelişme riskini belirlemek için yapılan çok değişkenli analiz sonucunda yaş, ECOG performans skoru, antibiyotik profilaksisi almamak, nötropenik atak sırasında pulmoner infiltrasyon varlığı ve indüksiyon ya da reindüksiyon kemoterapileri bağımsız risk faktörleri olarak saptandı. Bağımsız risk faktörlerinin regresyon katsayılarına göre puanlama yapıldı ve 6 puan ve üzeri yüksek riskli olarak belirlendi. Hastaların 60 günlük total sağ kalım ihtimali $\% 5,5$ olarak hesaplandı. TARTIŞMA ve SONUÇ: Bu çalışmada akut lösemi hastalarında solunum desteği ihtiyacının oldukça sık olduğu ve yüksek mortalite ile seyrettiği belirlendi. Yüksek riskli hastaların saptanabilmesinin önemli klinik faydaları olabileceği için geliştirdiğimiz risk skorlaması uygun çalışmalarla valide edilerek klinik pratikte kullanılabilir.
\end{abstract}

Anahtar Kelimeler: ALL, AML, Solunum yetmezliği, Risk

\begin{abstract}
INTRODUCTION: Acute leukemia is a group of heterogeneous diseases characterized by proliferation of blastic cells in bone marrow. and high mortality and morbidity are seen during the disease and treatment course. In these patients, respiratory failure are found that related to the high mortalities. In this study, we aimed to determine rate of respiratory support, prognostic factors and risk factors for acute leukemia.

METHODS: All acute leukemia patients followed in our center between 2003 and 2014 were included in this study, retrospectively. Extra-pulmonary causes (neurological causes, hemodynamic instability and cardiopulmonary arrest) which were excluded from the statistical calculations for risk analysis and prognosis. Demographic characteristics of patients, respiratory support rate and etiologies, risk factors for respiratory failure and prognostic factors were determined and overall survival of patients who needed respiratory support was determined.

RESULTS: Totally, 460 patients included to the study. The rate of respiratory support was $30.6 \%$ (139/460) and pneumonia was the most common cause of respiratory failure. In multivariate analysis, age, ECOG performance status, febrile neutropenia prophylaxis, pulmonary infiltration during neutropenia episode and induction or reinduction chemoterapies were determined as independent risk factors for respiratory failure in acute leukemia. A statistical model for risk prediction was developed based on regression coefficient of independent risk factors, and 6 points and more were considered as high risk. The 60-days overall survival of patients who needed mechanical ventilation was $5.5 \%$.
\end{abstract}


DISCUSSION AND CONCLUSION: In this study, we found that the need for respiratory support during acute leukemia treatment was quite frequent. As determination of high risk patients may provide important clinical benefits, validation of our risk scoring system by appropriately designed studies has utmost importance.

Keywords: ALL, AML, Respiratory failure, Risk

\section{GíRiș}

Akut lösemiler kemik iliğindeki lenfoid ve miyeloid immatür hücrelerin kontrolsüz çoğalmasıyla karakterize hastalıklardır. Son zamanlarda tedavi başarısı oranında artış olmakla birlikte halen yüksek mortalite ve morbiditeye sahiptirler. Akut myeloid lösemide (AML) 5 yıllık sağ kalım \% 15-30 arasında iken Akut lenfoblastik lösemide (ALL) 5 yıllık sağ kalım \% 40 olarak saptanmıştır (1-4). Mortalitenin en s1k sebebi pulmoner komplikasyonlardır. Akut lösemi hastalarında en sik görülen pulmoner komplikasyonlar; pnömoni, ATRA sendromu, lökostaz, pulmoner hemoraji gibi pulmoner infiltrasyonlarla seyreden durumlarındır $(5,6)$. Bu yüzden akut lösemi hastalarında pulmoner komplikasyon gelişimini tahmin edilmesi ve gerekli önlemlerin alınması son derece önemlidir. $\mathrm{Bu}$ çalışmada akut lösemi hastalarında solunum desteği gereksiniminin hangi sıklıkta ortaya çıktığını belirlemek, bu hastaların prognozunu ortaya koymak, solunum desteği ihtiyac1 duyacak hastaları ve prognozu tahmin etmek üzere istatistiksel modeller geliştirmek amaçlanmıştır.

\section{MATERYAL- METOD}

\section{Hastalar}

Bu çalışmada 2003-2014 tarihleri arasında Hacettepe Üniversitesi Tip Fakültesi (HÜTF) İç Hastalıkları Hematoloji Bilim Dalı'na başvuran ve en az 1 kür tedavi alan akut lösemi hastaları çalışmaya dâhil edilmiştir. Bu hastaların detaylı klinik ve laboratuvar bilgilerine hastanenin elektronik hasta kayıt veri tabanından retrospektif olarak ulaşıldı. Solunum desteği ihtiyacı duyulan hastaların detaylı klinik verileri kaydedildi. Solunum desteği için risk faktörlerini ve prognozu ortaya koymak üzere elde detaylı klinik verileri bulunan nötropeni epizodları belirlendi. Risk faktörleri ve prognozu belirleme aşamasında ekstrapulmoner sebeple yapılan solunum destekleri (Nörolojik sebepler, hemodinamik instabilite, kardiyopulmoner arrest) değerlendirmeye dâhil edilmedi.

\section{İstatistiksel Analiz}

Hasta kayıtları ve istatistiksel analizler için SPSS v18 (SPSS Inc., Chicago, Ill., ABD) kullanıldı. Kategorik değişkenler açısından fark olup olmadığı Ki kare testi ile değerlendirildi. Devamlı değişkenlerin istatistiksel kıyaslamasında eğer grup dağılımı anormal ve/veya vaka sayıs $<30$ ise Mann Whitney $U$, diğer hallerde ise $\mathrm{T}$ testi kullanıldı. Çok değişkenli analiz lojistik regresyon analizi ile yapıld1. Total sağ kalım hesaplamaları KaplanMeier yöntemine göre yapıldı. İstatistiksel kıyaslamalarda $\mathrm{P}$ değeri anlamlılık sınırı 0,05 olarak kabul edildi. Lojistik regresyon analizi sonuçlarına dayanılarak Sullivan ve arkadaşlarının tarif ettikleri yöntemle nötropeni epizodu sirasında solunum desteği ihtiyacı duyacak hastaları predikte etmeye yarayan skorlama sistemi geliştirildi (7). Bu yöntemde regresyon analizinde anlaml 1 bulunan parametrelerden regresyon katsayısı en düşük bulunan parametre 1 puan ile skorland. Diğer paramatreler regresyon katsayılarına göre oranlanarak puanlandı. Her puan düzeyi için modelin pozitif prediktivite, duyarlılık, negatif prediktivite ve özgüllük değerleri belirlendi. Böylelikle klinik kullanım için en uygun puanlama sisteminin saptanması amaçland. Lojistik regresyon analizi sonrası belirlenen modelin gerçek hayat verileri ile uyumu Hosmer ve Lemeshow testi ile değerlendirildi. Hosmer ve Lemeshow testi sonucunda $p>0,05$ çıkmasının modelin doğruluğunu gösterdiği kabul edildi.

$\mathrm{Bu}$ çalışma İç Hastalıkları uzmanlık tezinden üretilmiştir. Çalışma için HÜTF yerel etik kurulundan onay alınmıştır (Etik kurul karar no: GO 14/253-30, Onay tarihi: 30.4.2014).

\section{SONUÇLAR}

Çalışmaya 460 akut lösemi hastası dâhil edildi. Bu hastaların 308'i (\% 66,2) AML, 141'i (30.3 \%) ALL ve 12 hasta ise bifenotipik lösemiydi. Ortalama yaş AML hastalarında 48 (min-maks; 
16-66), ALL hastalarında ise 30 (min-maks 1776) olarak saptand. $\mathrm{Bu}$ hastalar bazal demografik ve klinik özellikleri özellikler Tablo 1 'de sunulmuştur. ALL hastalarında uygulanan başlıca kemoterapi protokolleri; CALGB-8811, Hiper-CVAD, BFM-95 ve HAM protokolleri idi. APL dışı AML hastalarında ise induksiyon ve re-induksiyon amaçlı kullanılan protokoller; idarubusin-ARA-C, mitoksantron-ARA-C $(3+7)$, mitoksantron-ARA-C $(2+5)$ ve EMA protokolleri idi. Konsolidasyon amaciyla ise yüksek doz ARA-C protokolu verilmişti. APL hastalarında ise AIDA ve LPA-2005 protokolleri uygulanmıştı.

Çalışmaya alınan 460 hastanın 139'una $(\% 30,3)$ solunum desteği uygulandığı saptand. Solunum desteği uygulanan hastaların ortanca yaş1 46 (min-maks, 17-86) idi. Solunum desteğinin nedeni $92(\% 54,8)$ hastada pnömoni, $11(\% 6,5)$ hastada lökostaz, $11(\% 6,5)$ hastada pulmoner hemoraji, 8 hastada pulmoner ödem, $7(\% 4,2)$ hasta ATRA sendromu, $11(\% 6,5)$ hastada nörolojik nedenler (intrakranial kanama, iskemik SVO, vs.), $6(\% 3,6)$ hastada hemodinamik instabilite, 17 (\% 10,2) hasta kardiyopulmoner arrest ve 4 (\%3) hastada ise sebebi belli olmayan nedenlere bağlı solunum yetmezliği gelişmişti. Dokuz hasta birden fazla kez solunum desteği ihtiyacı duydu. Onsekiz hastada (\% 12,9) non-invazi mekanik ventilasyon (NIMV), 93 hastada (\% 66,9) invazif mekanik ventilasyon (IMV) ve 28 hastada $(\% 20,1)$ ise önce NIMV, daha sonra ise başarısızlık nedeniyle İMV uygulandığı belirlendi.

Solunum desteği uygulanan 139 hastanın 19'unda $(\% 13,6)$ iyileşme saptandı. Solunum desteği olan hastalarda 60 günlük genel sağ kalım \% 5,5 olarak bulundu. Solunum desteği ihtiyacı duyan hastaların 60 günlük sağ kalım eğrileri Şekil 1'de verilmiştir.

Solunum desteği ihtiyacı gelişimi için risk faktörlerinin ve prognozun belirlenmesi için detaylı verilen bulunduğu 604 nötropeni epizodu belirlendi. Olası risk faktörleri için yapılan tek değişkenli analiz sonucunda Charlson komorbidite indeksi, nötropenik gün sayıs1, epizod sirasinda pulmoner infiltrasyon varlığı (Enfeksiyöz ve nonenfeksiyöz nedenlere bağl1), antibiyotik profilaksisi uygulanmaması, indüksiyon veya reindüksiyon amaciyla kemoterapi rejimi uygulanmas1, ECOG performans skoru ve diffüz pnömonik infiltrasyon mekanik ventilatör ile solunum Adress for correspondence: Hacettepe Üniversitesi Ankara - Türkiye Dr. Burak Bilgin e-mail: [drbbilgin@hotmail.com]

Available at www.actaoncologicaturcica.com

Copyright $\odot$ Ankara Onkoloji Hastanesi desteği uygulanması için anlamlı risk faktörleri olarak belirlenmiştir (Tablo 2).

Solunum desteği ihtiyacı gelişimi için risk faktörlerinin dâhil edildiği çok değişkenli analiz sonuçlarında ise antibiyotik profilaksisi uygulanmamas1, indüksiyon veya reindüksiyon kemoterapileri, ECOG performans skoru, yaş, epizod sırasında veya başlangıcında pulmoner infiltrasyon varlığ 1 solunum desteği için bağımsız risk faktörü olarak belirlenmiştir (Tablo 3).

Akut lösemi hastalarında solunum desteği ihtiyacının predikte etmek için risk modeli oluşturuldu. Bu modele göre en düşük regresyon katsayısına sahip olan ECOG skorunun 1'den büyük olması ve 40 yaşın üzerinde olmak 1 puan olarak puanladı, diğer parametrelerde regresyon katsayılarına göre oranlanarak; indüksiyon ve reindüksiyon rejimlerini almak ve epizod sirasinda pulmoner infiltrasyon varlığ 2 puan ve levofloksasin profilaksisi almamak 3 puan ile puanland. Toplam puan düzeyinin 6 veya üstünde olmasının solunum desteği için $\% 82$ sensitivite ve $\% 98$ spesifiviteye sahip olması nedeniyle yüksek riski belirlemek için eşik değer olarak kabul edildi. Bu modele göre 6, 7, 8 ve 9 puan alanlarda solunum yetmezliği gelişme ihtimali sirasiyla \% 13, \% 26, \% 46 ve \% 66 olarak bulundu. Geliştirilen bu model gerçek hayat verileri ile iyi uyum gösteriyordu (Hosmer ve Lemeshow testi, Ki kare= 8,173, p=0.417).

Solunum desteği uygulanan hastalarda iyi prognozu belirlemek için yapılan tek değişkenli analiz sonucunda cinsiyet, solunum desteğine başlama tipi, hastanın solunum desteğine başlandığında ki $\mathrm{pH}$ değeri, beyaz küre sayısı ve yoğun bakım kabulü istatistiksel olarak iyi prognoz açısından anlamlı olarak saptandi (Tablo 4).

Uygulanan solunum desteği ile sağkalım arasında ki ilişki incelendiğinde sadece NIMV uygulanan hastalar arasinda mortalite oranı en düşük olarak bulundu $(\%$ 43,6), IMV uygulanan hastalarda ki mortalite oran $\% 72,3$ bulunurken, NIMV uygulamasının yetersiz olmas1 nedeniyle IMV uygulanan hastalar arasında ise mortalite oranları en kötü olarak bulundu (\% 92). 
Tablo 1: Hastaların klinik özellikleri

\begin{tabular}{|l|l|l|}
\hline & AML & ALL \\
\hline Say1 & $308(\% 66,7)$ & $141(\% 30,3)$ \\
\hline $\begin{array}{l}\text { Yaş (ortanca, } \\
\text { min-maks) }\end{array}$ & $48(16-86)$ & $30(17-76)$ \\
\hline Cinsiyet (K/E) & $\begin{array}{l}118 / 188(\% 38,6 / \% \\
64,4)\end{array}$ & $\begin{array}{l}56 / 85(\% 39,7 / \% \\
60,3)\end{array}$ \\
\hline $\begin{array}{l}\text { Charlson } \\
\text { komorbidite indeksi } \\
\text { (median, min-maks) }\end{array}$ & $3(2-10)$ & $2(2-7)$ \\
\hline $\begin{array}{l}\text { Hastalık tipi (De } \\
\text { Novo- sekonder) }\end{array}$ & $262 / 44$ & $141 / 0$ \\
\hline
\end{tabular}

Tablo 2: Solunum desteği uygulanması için risk faktörlerinin tek değişkenli analiz sonuçları

\begin{tabular}{|c|c|c|c|}
\hline & \multicolumn{2}{|c|}{\begin{tabular}{|l} 
Solunum \\
Desteği
\end{tabular}} & \multirow[b]{2}{*}{$P$} \\
\hline & Var & Yok & \\
\hline $\begin{array}{l}\text { Yaş } \\
<40 \\
\geq 40\end{array}$ & $\begin{array}{l}53 \\
86\end{array}$ & $\begin{array}{l}154 \\
167\end{array}$ & 0,05 \\
\hline $\begin{array}{l}\text { Charlson komorbidite indeks } \\
\text { (ortalama } \pm \text { SD) }\end{array}$ & 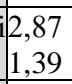 & $\begin{array}{l}3,2 \\
1,56 \\
\end{array}$ & 0,01 \\
\hline $\begin{array}{l}\text { Charlson komorbidite indeksi, yaş } \\
\text { hariç (ortalama } \pm \text { SD) }\end{array}$ & $\begin{array}{l}2,4 \\
0,81 \\
\end{array}$ & $\begin{array}{l} \pm 2,3 \\
\pm 0,68\end{array}$ & 0,02 \\
\hline $\begin{array}{l}\text { Kemoterapi tipi } \\
\text { İndüksiyon-reindüksiyon } \\
\text { Diğer }\end{array}$ & $\begin{array}{l}38 \\
12\end{array}$ & $\begin{array}{l}160 \\
394\end{array}$ & le, \\
\hline $\begin{array}{l}\text { Antibiyotik profilaksisi } \\
\text { Alan } \\
\text { Almayan } \\
\end{array}$ & 46 & $\begin{array}{l}245 \\
309 \\
\end{array}$ & < \\
\hline $\begin{array}{l}\mathrm{ECOG}^{*} \\
\quad \leq 1 \\
>1 \\
\end{array}$ & $\begin{array}{l}41 \\
9 \\
\end{array}$ & $\begin{array}{l}529 \\
30 \\
\end{array}$ & 0,01 \\
\hline $\begin{array}{l}\text { Nötropenik gün sayısı } \\
\text { (Ortalama } \pm \text { SD) }\end{array}$ & $\begin{array}{l}18 \\
9,9 \\
\end{array}$ & $\pm 15=$ & 0,03 \\
\hline $\begin{array}{l}\text { Pulmoner infiltrasyon } \\
\text { Var } \\
\text { Yok }\end{array}$ & $\begin{array}{l}24 \\
26\end{array}$ & $\begin{array}{l}58 \\
496\end{array}$ & < \\
\hline $\begin{array}{l}\text { İnfiltrasyon dağılımı } \\
\text { Diffüz } \\
\text { Lokal } \\
\end{array}$ & $\begin{array}{l}12 \\
12 \\
\end{array}$ & $\begin{array}{l}21 \\
37 \\
\end{array}$ & <, \\
\hline \begin{tabular}{|l|} 
Hastalık Tipi \\
AML \\
ALL \\
Bifenotipik \\
\end{tabular} & $\begin{array}{l}212 \\
94 \\
6\end{array}$ & $\begin{array}{l}84 \\
43 \\
6\end{array}$ & 0,267 \\
\hline \begin{tabular}{|l} 
Hastalık alt tipleri \\
Miyelomonositik \\
Burkitt \\
APL \\
Diğer \\
\end{tabular} & $\begin{array}{l}16 \\
6 \\
15 \\
96\end{array}$ & $\begin{array}{l}46 \\
10 \\
26 \\
229\end{array}$ & 0,609 \\
\hline
\end{tabular}

Tablo 3: Solunum desteği için risk faktörlerinin çok değişkenli analiz sonuçları

\begin{tabular}{|l|l|l|l|l|l|}
\hline Parametre & $\mathrm{B}$ & $\operatorname{Exp}(\mathrm{B})$ & $P$ & \multicolumn{2}{|l|}{ GA \%95 } \\
\hline $\begin{array}{l}\text { Charlson kt Alt } \\
\text { indeksi }\end{array}$ & $-0,22$ & 0,8 & 0,380 & 0,507 & 1,504 \\
\hline Nötropenik gün say1s1 & 0,005 & 1,005 & 0,728 & 0,976 & 1,035 \\
\hline $\begin{array}{l}\text { Antibiyotik profilaksisi } \\
\text { almamas1 }\end{array}$ & 2,326 & 10,02 & $\begin{array}{l}0,01 \\
0 \text { lmorbidite }\end{array}$ & 3,142 & 33,336 \\
\hline
\end{tabular}

Adress for correspondence: Hacettepe Üniversitesi Ankara - Türkiye Dr. Burak Bilgin e-mail: [drbbilgin@hotmail.com]

Available at www.actaoncologicaturcica.con

Copyright $\odot$ Ankara Onkoloji Hastanesi

\begin{tabular}{|c|c|c|c|c|c|}
\hline performans & $\mid 0,999$ & 2,71 & 0,087 & 0,865 & 8,53 \\
\hline Pulmoner infiltrasyon & $\mid 1,781$ : & 15,93 & 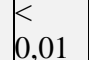 & 2,36 & 14,9 \\
\hline Yaş & 0,87 & 2,38 & 0,048 & 1,008 & 5,65 \\
\hline $\begin{array}{l}\text { Kemoterapi } \\
\text { tipi(İndüksiyon veya } \\
\text { reindüksiyon/ diğer) }\end{array}$ & $a 2,003$ & 37,41 & 0,01 & 3,37 & 16,2 \\
\hline $\begin{array}{ll}\text { Pnömoni } & \text { dağılım } \\
\text { (diffüz/lokal) } & \end{array}$ & & 1,208 & 0,75 & 0,37 & 3,9 \\
\hline
\end{tabular}

Tablo 4: Solunum desteği ihtiyacının düzelmesini predikte eden faktörler

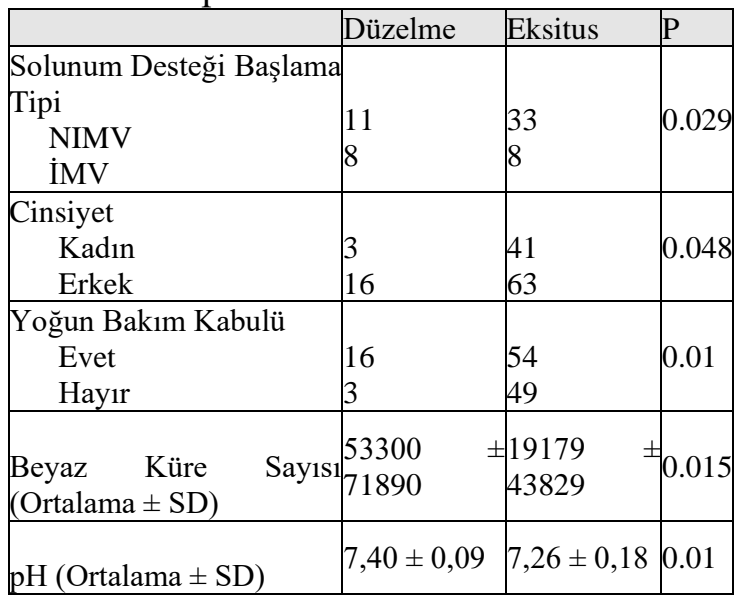

\section{TARTIŞMA}

Akut lösemilerde solunum yetmezliğinin nadir bir komplikasyon olarak bilinmesine rağmen bizim bulduğumu verilere göre tahmin edilenden daha sık görülebilmektedir. Al-ameri ve arkadaşlarının yaptığı çalışmada induksiyon kemotropisi alan hastalarda ki ile ilk 2 haftalık süreçte solunum yetmezliği gelişim oranını $\% 8$ olarak saptamışlardır (8). Bizim çalışmamızda ise bu oran \% 30,3 olarak saptanmıştır. Arada ki fark muhtemelen bizim çalışmamızda tüm hasta gruplarının alınması ve süre limiti konulmaması ile ilişkilidir.

Yaptığımız çalışmada solunum yetmezliğinin başlica nedeni ise pulmoner enfeksiyonlar olarak saptadık. Pulmoner hemoraji, lokostaz, ATRA sendromu, kardiyopulmoner arrest ise diğer etyolojik sebepler olarak saptandi. Bununla birlikte birçok hastada birden fazla etken beraber olarak bulunmaktaydı. Daha önce yapılan çalışmalarda da bizim çalışmamıza benzer olarak en sık solunum yetmezliği nedeninin enfeksiyonlar olduğu saptanmıştır $(5,8)$. Bununla birlikte bazı çalışmalarda gram pozitif etkenler daha sık 
olarak bulunurken bazılarında ise gram negatif etkenler daha sık olarak saptanmıştır $(9,10)$.

Akut lösemi hastalarında solunum yetmezliği gelişimi için risk faktörlerinin belirlenmesi için yapılan Al-ameri ve arkadaşlarının yaptığı çalışmada erkek cinsiyet, APL, performans skorunun kötü olması, tanı anında pulmoner infiltrasyon varlığ 1 ve yüksek kreatinin düzeyi bağımsız risk faktörleri olarak saptanmıştır (8). Yine aynı çalışmada var olan risk faktörlerinin sayısına göre skorlama yapılmış ve 1, 2, 3, 4-5 risk faktörü varlığında tahmini solunum yetmezliği insidansı sırasıyla $\%$ 3, \% 13, \% 23, \% 34 olarak saptanmıştır. Müslimani ve arkadaşlarının yaptığ 1 çalışmada ise indüksiyon tedavisi surasında gelişen pulmoner infiltrasyonların varlığında $\% 50$ oranında solunum desteği ihtiyacı geliştiğini saptamıştır (6). Bizim yaptığımız çalışmada ise 40 yaşın üzerinde olmak, ECOG performans skorunun kötü olmasi, levofloksasin profilaksisi almamak, indüksiyon veya reindüksiyon kemoterapisi almak ve epizod sirasinda pulmoner infiltrasyon varlığı bağımsız risk faktörü olarak tespit edildi. Solunum yetmezliği için en önemli risk faktörü olarak antibiyotik profilaksisi uygulanmaması bulundu. Bu bulgu daha önce yapılan birçok çalışma sonuçlarıyla benzerlik göstermektedir (11-13). Tüm bu bulduğumuz veriler 1şığında hangi hastada solunum desteği ihtiyac1 gelişeceğini predikte etmek için bir model oluşturuldu. Bu modelde 6 puan sinır olarak kabul edildi. Sensitivite, spesivite, pozitif ve negatif prediktivite değerleri en ideal olan 6 ve üzeri puan alan hastaların solunum yetmezliği için yüksek risk altında olduklarını saptand. Bu modele göre 6 , 7,8 ve 9 puan alanlarda solunum yetmezliği gelişme ihtimali sırasıyla $\% 13, \% 26, \% 46$ ve $\% 66$ olarak bulundu. Al ameri ve arkadaşlarının yaptığı skorlamala sisteminden farklı olarak bizim çalışmamızda skorlama risk faktörlerinin sayısına göre değil çok değişkenli analiz sonucunda bağımsız risk faktörü olarak kabul edilen parametrelerinin regreyon katsayıları oranına göre puanlanarak yapıldı (8). Yapılan çalışmalarda solunum desteği uygulamasının akut lösemilerde hastalık durumundan bağımsız olarak kötü prognostik bir belirteç olduğu bilinmektedir. Şu ana kadar yapılan tüm çalışmalarda mortalite oranını $\% 75$ - 100 arasında değişen değerlerde tespit edilmiştir $(8,14)$. Bizim çalışmamızda bulduğumuz 60 günlük total sağ kalım oranının

Adress for correspondence: Hacettepe Üniversitesi Ankara - Türkiye Dr. Burak Bilgin e-mail: [drbbilgin@hotmail.com]

Available at www.actaoncologicaturcica.com

Copyright $\mathbb{C}$ Ankara Onkoloji Hastanesi
$\%$ 5,5 olması da literatür verilerine uygun olarak saptanmıştır. Daha önce yapılmış olan çalışmalarda NIMV uygulamasının entübasyonu geciktirdiği, ventilatör ilişkili komplikasyonları azalttığı, yoğun bakım ve hastanede kalış süresini kısalttığı ve sonuncu olarak mortalite üzerine olumlu etkileri saptanmıştır $(5,15,16)$. Depuydt ve arkadaşlarının yaptığ çalışmada ise ciddi solunum yetmezliği olan hastalarda NIMV ile IMV uygulamalarının karşılaştırıldığında mortalite üzerine benzer etkileri olduğu saptandi. Bununla birlikte NIMV uygulamasının başarısız olduğu durumlarda mortalite oranı çok daha yüksek olduğu yapılan çalışmalarda bulunmuştur (17). Bunun başlıca nedeni hastalara yeterli solunum desteği uygulanamamasıdır. Yapılan çalışmalarda agresif solunum desteği ihtiyacı olan hastalarda ilk 24 saat içinde IMMV uygulamasının mortalite üzerine olumlu etkileri saptanmıştır (18). Bizim yaptığımız çalışmada da benzer olarak sadece NIMV uygulanan grupta mortalite en iyi olarak saptanırken NIMV sonrası İMV uygulanan grupta mortalite oranları en kötü olarak bulundu.

Çalışmamızın retrospektif olarak gerçekleştirilmesi; APACHE, SOFA gibi prognostik skorlara ulaşılamadığı için değerlendirmeye alınamaması başlıca k1sitl11ıklardır. Bununla birlikte geniş hasta popülasyonu ile gerçekleştirmiş olması ve Türkiye'de bu konuda daha önce yapılmış çalışma olmaması nedeniyle bu çalışma sonuçlarının önemli olduğu düşünülmektedir.

Sonuçta akut lösemi hastalarında solunum desteği ihtiyacının oldukça sık olduğu ve yüksek mortalite ile seyrettiği belirlendi. Yüksek riskli hastaların saptanabilmesinin önemli klinik faydaları olabileceği için geliştirdiğimiz risk skorlamasının uygun çalışmalarla validasyonu çok önemlidir.

Conflict of Interest: The authors declare that they have no conflict of interest.

\section{REFERANSLAR}

1. Mrozek K, Marcucci G, Nicolet D, et al. Prognostic significance of the European LeukemiaNet standardized system for reporting cytogenetic and molecular alterations in adults with acute myeloid leukemia. Journal of clinical oncology : official journal of the American 
Society of Clinical Oncology 2012; 30:45154523

2. Goker H, Ozdemir E, Uz B, et al. Comparative outcome of reduced intensity and myeloablative conditioning regimen in HLA identical sibling allogeneic hematopoietic stem cell transplantation for acute leukemia patients: a single center experience. Transfusion and apheresis science : official journal of the World Apheresis Association : official journal of the European Society for Haemapheresis 2013; 49:590-599

3. Ludwig WD, Rieder $\mathrm{H}$, Bartram CR, et al. Immunophenotypic and genotypic features, clinical characteristics, and treatment outcome of adult pro-B acute lymphoblastic leukemia: results of the German multicenter trials GMALL 03/87 and 04/89. Blood 1998; 92:1898-1909

4. Serefhanoğlu S. Rutin Klinik Pratikte Akut Lösemi: 2003-2008 Yılları Arasında izlenen Akut Lösemi Hastalarının Analizi.: Heamatology, Hacettepe University; 2009.

5. Bird GT, Farquhar-Smith P, Wigmore T, et al. Outcomes and prognostic factors in patients with haematological malignancy admitted to a specialist cancer intensive care unit: a $5 \mathrm{yr}$ study. British journal of anaesthesia 2012; 108:452459

6. Muslimani A, Chisti MM, Margolis J, et al. Pulmonary Infiltrates in Acute Myeloid Leukemia During Induction Treatment: How Much Do We Know? American journal of clinical oncology 2013;

7. Sullivan LM, Massaro JM, D'Agostino RB, Sr. Presentation of multivariate data for clinical use: The Framingham Study risk score functions. Statistics in medicine 2004; 23:1631-1660

8. Al Ameri A, Koller C, Kantarjian H, et al. Acute pulmonary failure during remission induction chemotherapy in adults with acute myeloid leukemia or high-risk myelodysplastic syndrome. Cancer 2010; 116:93-97

9. Specchia G, Pastore D, Carluccio P, et al. Pneumonia in acute leukemia patients during induction therapy: experience in a single institution. Leukemia \& lymphoma 2003; 44:97101

10. Rossini F, Verga M, Pioltelli $\mathrm{P}$, et al. Incidence and outcome of pneumonia in patients with acute leukemia receiving first induction therapy with anthracycline-containing regimens. Haematologica 2000; 85:1255-1260

11. Reuter S, Kern WV, Sigge A, et al. Impact of fluoroquinolone prophylaxis on reduced infection-related mortality among patients with neutropenia and hematologic malignancies. Clinical infectious diseases : an official publication of the Infectious Diseases Society of America 2005; 40:1087-1093

12. Gafter-Gvili A FA, Paul M, Vidal L, et al. Antibiotic prophylaxis for bacterial infections in afebrile neutropenic patients following chemotherapy (Review). The Cochrane Library 2012;

13. Etgül S. Hematolojik kanserli hastalarda kinolon profilaksisinin morbidite, mortalite ve fekal

Adress for correspondence: Hacettepe Üniversitesi Ankara - Türkiye Dr. Burak Bilgin e-mail: [drbbilgin@hotmail.com]

Available at www.actaoncologicaturcica.com

Copyright $\odot$ Ankara Onkoloji Hastanesi kinolon dirençli E. coli kolonizasyonuna etkisi, Hacettepe University; 2013.

14. Groeger JS, White P, Jr., Nierman DM, et al. Outcome for cancer patients requiring mechanical ventilation. Journal of clinical oncology : official journal of the American Society of Clinical Oncology 1999; 17:991-997

15. Hilbert G, Gruson D, Vargas F, et al. Noninvasive ventilation in immunosuppressed patients with pulmonary infiltrates, fever, and acute respiratory failure. The New England journal of medicine 2001; 344:481-487

16. Gristina GR, Antonelli M, Conti G, et al. Noninvasive versus invasive ventilation for acute respiratory failure in patients with hematologic malignancies: a 5-year multicenter observational survey. Critical care medicine 2011; 39:2232-2239

17. Depuydt PO, Benoit DD, Vandewoude KH, et al FA. Outcome in noninvasively and invasively ventilated hematologic patients with acute respiratory failure. Chest 2004; 126:1299-1306

18. Price KJ, Cardenas-Turanzas $\mathrm{M}$, Lin $\mathrm{H}$, et al. Prognostic indicators of mortality of mechanically ventilated patients with acute leukemia in a comprehensive cancer center. Minerva anestesiologica 2013; 79:147-155 